\title{
Endoscopic removal of two long iron rods impacted in the stomach
}

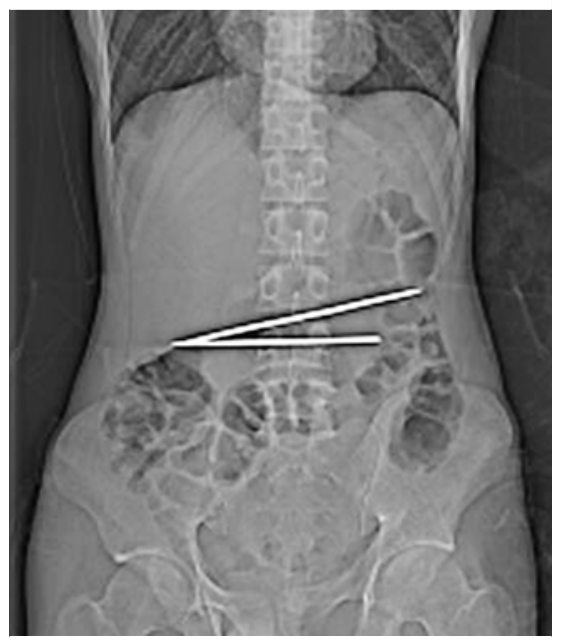

- Fig. 1 Two long rods impacted in the stomach as shown on abdominal imaging.

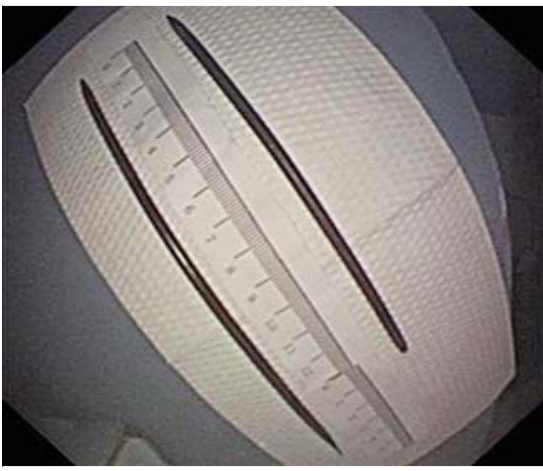

Fig. 3 The two rods of more than $10 \mathrm{~cm}$ in length, after removal.

A 20-year-old man was referred for left epigastralgia, with a history of eating barbecued food and alcoholic intoxication 2 days earlier. On physical examination, he had abdominal tension and tenderness, without obvious rebound pain. Abdominal imaging revealed two long rods $(17 \mathrm{~cm}$ and $13 \mathrm{~cm})$ in the stomach, without signs of perforation or other conditions (\ Fig. 1). Upper endoscopy revealed that the proximal ends of the iron rods were impacted in the gastric body ( $>$ Fig. 2 a), while the distal ends were impacted in the gastric an-

tr-

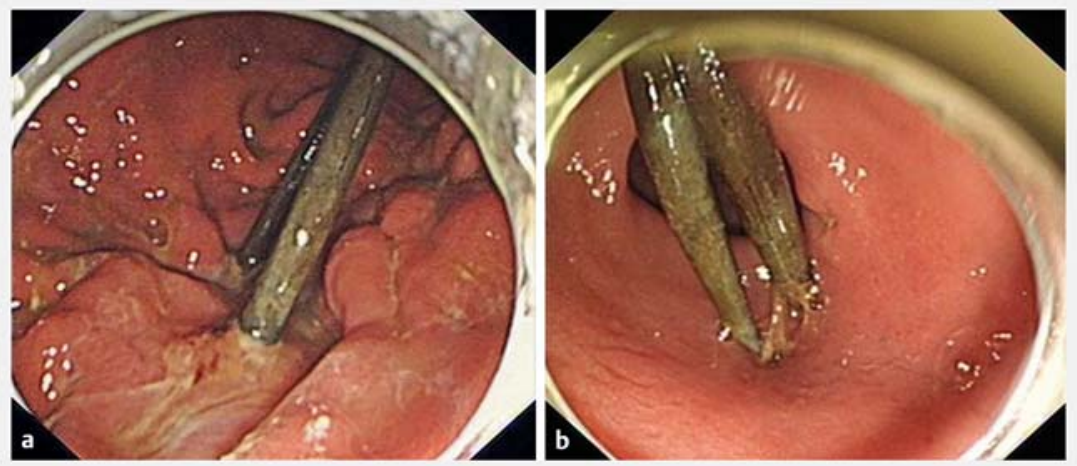

Fig. 2 a The proximal ends of the rods impacted in the gastric body. $\mathbf{b}$ The distal ends of the rods impacted in the gastric antrum

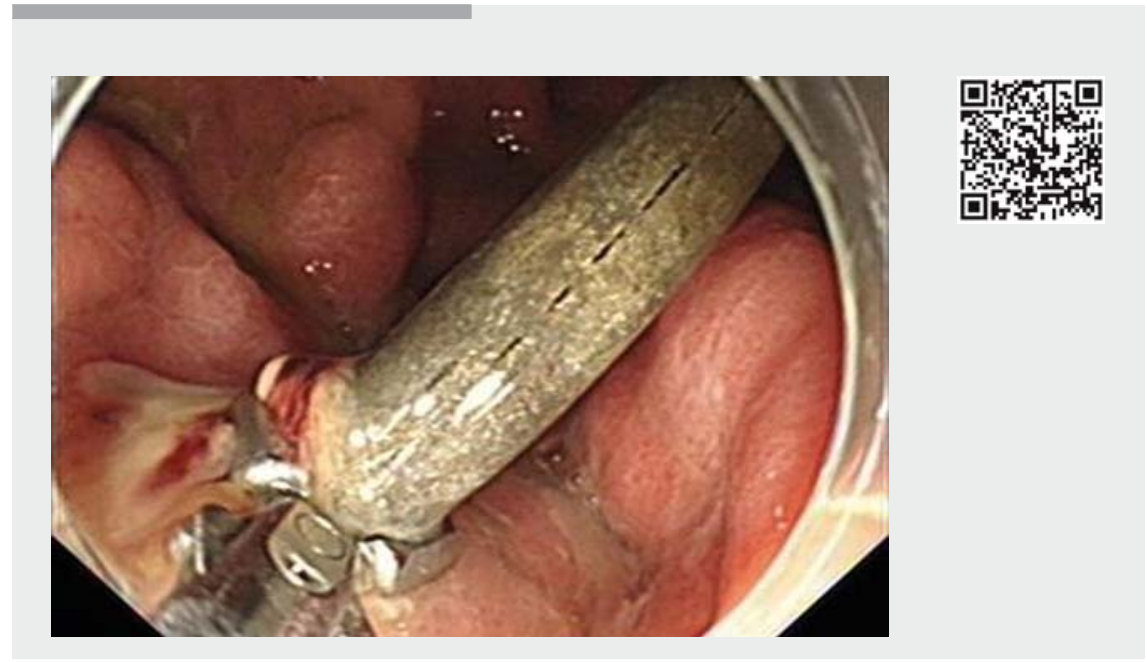

$\nabla$ Video 1 Endoscopic removal, by means of grasping forceps, of two long iron rods impacted in the stomach.

um (\Fig.2b). We used endoscopic grasping forceps to gently grip the proximal ends of the rods and remove them as we withdrew the endoscope ( $\mathbf{F i g . 3 ,}$ - Video 1). There was no perforation, and only surrounding mucosal hyperemia and edema were noted. The patient's symptoms disappeared, and he was discharged from our hospital on the same day.

Ingested long foreign bodies are always associated with high rates of perforation, and urgent endoscopic intervention is strongly recommended [1]. A snare, basket, overtube, or even a double-channel endoscope may be helpful to remove such long objects [2,3]; however, it is extremely difficult to remove objects longer than $10 \mathrm{~cm}$, and surgery is frequently required [3]. In the present case, we demonstrated the use of grasping forceps for successful removal of two iron rods that were more than $10 \mathrm{~cm}$ in length, each with both ends impacted in 
the stomach. We suggest that grasping forceps can also play a positive role in the extraction of impacted long foreign bodies. Maneuvering the proximal end of the object into the transparent cap of the endoscope is beneficial for preventing mucosal injury.

Endoscopy_UCTN_Code_TTT_1AO_2AL

Acknowledgments

We acknowledge the help of our endoscopy center in the management of our patient. This study was funded by Sichuan Province Science and Technology Department (China) (Grant Number: 2017SZ0009).

\section{Competing interests}

All authors disclose no conflicts relevant to this article.

The authors

\section{Liansong Ye", Xianhui Zeng", Xuli Wang, Chuanjun Tang, Jiang Du, Yuhang Zhang, Bing Hu \\ Department of Gastroenterology, West China Hospital, Sichuan University, Chengdu, China}

* These authors contributed equally to this work.

\section{Corresponding author}

\section{Bing Hu, MD}

Department of Gastroenterology, West China Hospital, Sichuan University, No. 37 Guo Xue Xiang, Wu Hou District, Chengdu, Sichuan 610041, China

hubingnj@163.com

Fax: +86-028-85423387

\section{References}

[1] Birk M, Bauerfeind P, Deprez PH et al. Removal of foreign bodies in the upper gastrointestinal tract in adults: European Society of Gastrointestinal Endoscopy (ESGE) Clinical Guideline. Endoscopy 2016; 48: 489-496

[2] Ikenberry SO, Jue TL, Anderson MA et al. Management of ingested foreign bodies and food impactions. Gastrointest Endosc 2011; 73: $1085-1091$

[3] Li ZS, Sun ZX, Zou DW et al. Endoscopic management of foreign bodies in the upperGI tract: experience with 1088 cases in China. Gastrointest Endosc 2006; 64: 485-492

\section{Bibliography}

DOI https://doi.org/10.1055/a-0824-6087

Published online: 18.1.2019

Endoscopy 2019; 51: E71-E72

(c) Georg Thieme Verlag KG

Stuttgart · New York

ISSN 0013-726X

\section{ENDOSCOPY E-VIDEOS}

https://eref.thieme.de/e-videos access online section, reporting on interesting cases and new

techniques in gastroenterological endoscopy. All papers include a high quality video and all contributions are freely accessible online.

This section has its own submission website at https://mc.manuscriptcentral.com/e-videos 